\title{
Molecular Analysis of KPC and GES Beta-Lactamase Genes in Clinical Isolates of Klebsiella pneumoniae by PCR Method
}

\section{Running Title: KPC and GES Genes in Klebsiella pneumoniae}

\author{
Marzieh Saremi $^{1}$, Leila Saremi ${ }^{2}$, Sepideh Babaniamansour ${ }^{3}$, Razieh Nazari $^{4}$, Zohreh Saltanatpour $^{5 *}$ (D) \\ ${ }^{1} \mathrm{MS}$, Department of Microbiology, Qom branch, Islamic Azad University, Qom, Iran. \\ ${ }^{2} \mathrm{PhD}$, Department of Biology, Science and Research Branch, Islamic Azad University, Tehran, Iran. \\ ${ }^{3} \mathrm{MD}$, School of Medicine, Islamic Azad University Tehran Faculty of Medicine, Tehran, Iran \\ ${ }^{4} \mathrm{PhD}$, Department of Microbiology, Qom branch, Islamic Azad University, Qom, Iran. \\ ${ }^{5} \mathrm{PhD}$, Pediatric Cell Therapy Research Center, Stem Cell and Regenerative Medicine Center of Excellence, Tehran University of Medical Sciences, \\ Tehran, Iran.
}

*Corresponding author: Zohreh Saltanatpour, PhD, Pediatric Cell Therapy Research Center, Stem Cell and Regenerative Medicine Center of Excellence, Tehran University of Medical Sciences, Tehran, Iran. ORCID: 0000-0002-1616-9404.

Received date: June 17, 2021; Accepted date: August 17, 2021; Published date: August 23, 2021

Citation: M Saremi, L Saremi, S Babaniamansour, R Nazari, Z Saltanatpour. (2021) Molecular Analysis of KPC and GES Beta-Lactamase Genes in Clinical Isolates of Klebsiella pneumoniae by PCR Method. International Journal of Clinical Case Reports and Reviews. 8(2); DOI:10.31579/2690-4861/149

Copyright: () 2021 Zohreh Saltanatpour, This is an open-access article distributed under the terms of the Creative Commons Attribution License, which permits unrestricted use, distribution, and reproduction in any medium, provided the original author and source are credited.

\begin{abstract}
Background: Carbapenem-resistant Klebsiella pneumonia (K. pneumoniae) has been recently identified as the major class of pathogens and the treatment became the biggest challenge in this bacterium. We assessed the antibiotic resistance patterns of $\mathrm{K}$. pneumoniae, the frequency of resistant strains to imipenem, meropenem, and ertapenem, and the frequency of K. pneumoniae carbapenemases (KPC), and Guiana-Extended-Spectrum (GES) metallo- $\beta$-lactamase genes.
\end{abstract}

Methods: The phenotypes of 200 strains of K. pneumonia, collected from 650 clinical samples, were isolating and identified in Qom, Iran. The antibiotic resistance pattern of the strains was analyzed against different antibiotics. The imipenem, meropenem, and ertapenem-resistant strains, were isolated and the frequency of KPC and GES genes were evaluated.

Results: K. pneumoniae strains had different resistance patterns against various antibiotics. The isolated strains with the highest and lowest antibiotic resistance were related to ampicillin, and meropenem, respectively. Investigation of the KPC and GES $\beta$ lactamase showed that none of 48 imipenem, meropenem, and ertapenem-resistance isolates had the KPC gene. In addition, the GES gene was detected in 3(2.7\%) of 110 ceftazidime-resistant specimens.

Conclusions: Carbapenem is useful in the treatment of $\mathrm{K}$. pneumoniae infections. Due to the importance of the mechanisms of resistance is by $\beta$-lactamase genes, investigating the prevalence of $\beta$-lactamase genes can help to increase the necessity of choosing the appropriate treatment for K. pneumoniae.

Keywords: klebsiella pneumonia; $\beta$-lactamases; kpc; ges

\section{Introduction}

Carbapenemase-producing Klebsiella pneumonia causes a wide range of infections, including types of pneumonia, urinary tract infections, liver abscesses. K. pneumoniae carbapenemases (KPC) are $\beta$-lactamases produced by Gram-negative bacteria. They efficiently hydrolyze all cephalosporins, penicillins, monobactams, $\beta$-lactamase inhibitors, and carbapenems. Since the first reports, KPC enzymes have spread across the world, although the expansion varied by geographical locations $[1,2]$. 
The high prevalence of broad-spectrum $\beta$-lactamases in $\mathrm{K}$. pneumoniae isolated from clinical specimens of patients led to the spread of antibiotic resistance while antibiotics in the $\beta$-lactam group account for the high proportion of antibiotics used in medicine. The emerging antibiotic resistance caused an important challenge in the management of $\mathrm{K}$. pneumonia-related diseases [3-5].

The fluoroquinolones, trimethoprim-sulfamethoxazole, and cephalosporins are mostly used for the treatment of $\mathrm{K}$. pneumoniae infections, and resistance to these antibiotics caused the treatment problems and subsequently increased mortality. Resistance bacteria to $\beta$ lactam antibiotics obtains through the mutation in chromosomal genes or the transfer of plasmids. $\beta$-lactamase is an enzyme non-covalently links to the antibiotics containing the $\beta$-lactam ring and finally inactivates them [6-8].

Carbapenems such as meropenem, imipenem, and ertapenem are resistant to many $\beta$-lactamases, as well as class 1 chromosome $\beta$-lactamases (which destroy third-generation cephalosporins). $\beta$-lactamases can decompose and hydrolyze $\beta$-lactam antibiotics and cannot be inhibited by $\beta$-lactamase inhibitors $[9,10]$.

In K. pneumoniae, various groups of $\beta$-lactamases have been identified, such as KPC and GES (Guiana-Extended-Spectrum). These enzymes are usually transferred by integrons. The ability to transfer and hydrolyze the carbapenems made the antibiotics ineffective $[11,12]$

KPC hydrolyses the $\beta$-lactam drugs, including monobactam, carbapenem, and third-generation falosporin. The producer gene is located on the plasmid and can transfer to many bacteria [13]. GES was first discovered in 2000 in a clinical specimen of K. pneumoniae isolated from Guiana, France. Nine enzymes of GES type have been identified in different species of pathogens such as Pseudomonas aeruginosa. GES-1 has the same hydrolytic activity as an extended-spectrum $\beta$-lactamase and is inhibited by $\beta$-lactamase inhibitors. GES-2, GES-4, GES-5, and GES- 6 enzymes have also hydrolytic activity against carbapenems. GES-1, GES5, GES-8, and GES-9 enzymes were reported in Pseudomonas aeruginosa [14-16].

Following the growing population of gram-negative organisms producing $\beta$-lactamases, there are numerous reports of widespread outbreaks, especially in the intensive care unit. The Center for Disease Control and Prevention has proposed the Polymerase chain reaction (PCR) and RealTime PCR tests and sequencing to the microbiologists to identify these resistance producer genes, and in 2011, many scholars have used these methods. Herein, this study aimed to assess the antibiotic resistance patterns of $\mathrm{K}$. pneumoniae, the frequency of resistant strains to meropenem, imipenem, and ertapenem, as well as the frequency of KPC and GES metallo- $\beta$-lactamase genes.

\section{Methodology}

\section{Study design}

This study was conducted among the patients hospitalized in various wards and different hospitals of Qom city, Iran, during October 2016 and September 2017. The executive protocol of the study was approved by the ethics committee of Qom Islamic Azad University of Medical Sciences approved the executive protocol of the study. The study was conducted under the Declaration of Helsinki (seventh revision 2013). The written consent was taken from all participants before entering the study and under the direction of the Iranian Foundation of Martyrs and Veterans Affairs review board. This study did not impose any additional costs on the patients or the health system.

\section{Sampling}

The participants were asked to fill out the demographic questionnaire including gender, age, duration and ward of hospitalization, type of disease, and type of clinical specimen. Samples were taken from blood, urine, burn wounds, surgical wounds, respiratory secretions, cerebrospinal fluid, clones, and general secretions (ears, nose, and eyes). Samples were immediately transferred to the research laboratory of Qom Islamic Azad University. The samples were cultured in a MacConkey agar with a selective and differential medium. In this environment, bile salts and violet crystals inhibit the growth of gram-positive bacteria that are used for this purpose. Then the colonies, morphologically similar to $\mathrm{K}$. pneumoniae, were selected and used for further investigations.

\section{Isolation and identification of K. pneumoniae}

A few bacterial colonies were removed from the solid medium, were placed along with a drop of the physiological serum on a clean slide, and were fixed by spreading and drying. Then the crystal violet was poured onto the slide and was washed with water for one minute. In the next step, the extension was adjacent to the logo for one minute and after washing the slide with water, the de-staining step was carried out with alcohol. After washing with water, slides were stained with fuchsin for 30 seconds and then thoroughly washed and dried. Finally, the slides were examined to detect the presence of gram-negative bacilli by optical microscopy. The colonies in the gram-negative bacterial staining were streaking on the agar media several times, to be completely pure. After gram staining on singlecell colonies and ensuring their purity, differential tests were performed to detect $\mathrm{K}$. pneumoniae as following:

\section{Triple Sugar Iron (TSI) test}

The TSI test is used to determine whether gram-negative bacteria can to utilize lactose, glucose, sucrose and also used to generate hydrogen sulfide. After the deep and superficial cultivation of the bacteria in the TSI environment, the culture medium is incubated at $37^{\circ} \mathrm{C}$ for 24 hours.

\section{Catalase test}

The catalase enzymes mediate the breakdown of hydrogen peroxide into water and oxygen. A small amount of bacterial colony is transferred to the surface of a clean and dry glass slide using a loop. A drop of $3 \% \mathrm{H}_{2} \mathrm{O}_{2}$ is added and placed on the glass slide. The positive test defines as the appearance of oxygen gas bubbles on the glass slide.

\section{Citrate test}

The citrate test is applied to determine the ability of K. pneumoniae to use ammonium salt as a source of nitrogen and sodium citrate as a source of carbon. K. pneumoniae that grows in the medium changes the medium alkaline. A pure colony was removed from the media and diagonally cultured on a tube containing the citrate. The appearance of a dark blue color after 24 to 48 hours at $37^{\circ} \mathrm{C}$ indicates the consumption of citrate by the organism and the positive test. Moreover, the Methyl Red and Voges-Proskauer and Sulfiter Indole Motility tests were performed based on the study conducted by Yumi et al. [17].

\section{Oxidase test}

The oxidase test is used to identify the bacteria that produce cytochrome $\mathrm{c}$ oxidase. The cytochrome c oxidase oxidizes the reagent (tetramethyl-pphenylenediamine) to (indophenols) purple color end product. Therefore, one drop of reagent oxidase is placed on a filter paper, and some bacterial colonies are placed on it. After a few seconds, the absence of color change represents the negative test.

\section{Antibiotic sensitivity test}

According to the Clinical and Laboratory Standards Institute guidelines, the antibiotic resistance of the strains against selected antibiotics is evaluated by a Kirby-Bauer disc method. (Table 1). 


\begin{tabular}{|c|c|}
\hline Antibiotic & Concentration \\
\hline Ceftriaxone & $30 \mu \mathrm{g}$ \\
\hline Ceftazidime & $30 \mu \mathrm{g}$ \\
\hline Gentamicin & $10 \mu \mathrm{g}$ \\
\hline Amikacin & $30 \mu \mathrm{g}$ \\
\hline Ciprofloxacin & $5 \mu \mathrm{g}$ \\
\hline Piperacillin & $100 \mu \mathrm{g}$ \\
\hline Piperacillin-Tazobactam & $100 \mu \mathrm{g} / 10 \mu \mathrm{g}$ \\
\hline Imipenem & $10 \mu \mathrm{g}$ \\
\hline Meropenem & $10 \mu \mathrm{g}$ \\
\hline Ertapenem & $10 \mu \mathrm{g}$ \\
\hline Ceftizoxime & $30 \mathrm{unit}$ \\
\hline Aztreonam & $30 \mu \mathrm{g}$ \\
\hline Cefepime & $30 \mu \mathrm{g}$ \\
\hline Levofloxacin & $25 \mu \mathrm{g}$ \\
\hline Arimethoprim - sulfamethoxazole & $5 \mu \mathrm{g}$ \\
\hline Ampicillin - sulbactam & $10 \mu \mathrm{g} / 10 \mu \mathrm{g}$ \\
\hline Ticarcillin - clavulanic acid & $75 \mu \mathrm{g} / 10 \mu \mathrm{g}$ \\
\hline Amoxicillin & $10 \mu \mathrm{g}$ \\
\hline Cefotaxime & $30 \mu \mathrm{g}$ \\
\hline Ampicillin & $30 \mu \mathrm{g}$ \\
\hline Ticarcillin & $30 \mu \mathrm{g}$ \\
\hline Amoxicillin-clavulanic acid & $75 \mu \mathrm{g} / 10 \mu \mathrm{g}$ \\
\hline
\end{tabular}

Table 1: Antibiotic discs used in antibiotic sensitivity test

\section{The phenotypic identification of $\boldsymbol{\beta}$-lactamase strains}

The Double Disk Synergy Test was used to isolate $\beta$-lactamase producing strains. $5 \mathrm{ml}$ of the ethylenediaminetetraacetic acid (EDTA) 0.5 -mole solution is added to the imipenem disks. It is incubated at $4{ }^{\circ} \mathrm{C}$ for 12 weeks after the drying. Imipenem-resistant strains were cultured on the Muller Hinton medium. Then, an imipenem disk $(10 \mu \mathrm{g})$ containing 930 $\mu \mathrm{g}$ EDTA was placed at an appropriate distance on the plate surface and incubated at $37{ }^{\circ} \mathrm{C}$ for 18 to 16 hours. An increase in the diameter of inhibition zone diameter, $\leq 7 \mathrm{~mm}$ around the imipenem disk containing
EDTA, is compared to the imipenem disk alone. The results indicated the production of Metallo- $\beta$-lactamase.

Molecular analysis of $\boldsymbol{\beta}$-lactamase genes in $\mathrm{K}$. pneumoniae strains isolated by PCR method

PCR method was used for molecular detection of $\beta$-lactamase genes in K. pneumoniae isolated from clinical specimens. In this study, two genes of KPC and GES were selected for molecular analysis. The sequences of these primers were studied in numerous papers and their thermodynamic properties were evaluated using Gene Runner software and synthesized (Table 2).

\begin{tabular}{|c|c|}
\hline Primer type & Sequence \\
\hline KPC F & 5' GTG CAC TGT ATC GCC GTC TAG 3 \\
\hline KPC R & 5' TTA CTG CCC GTT GAC GCC CAA TCC 3' \\
\hline GES F & 5' ATGCGCTTCATTCACGCAC3' \\
\hline GES R & 5' CTATTTGTCCGTGCTCAGG 3' \\
\hline
\end{tabular}

KPC: K. pneumoniae carbapenemases; GES: Guiana-Extended-Spectrum.

Table 2: The sequence of specific primers for molecular analysis

Bacterial deoxyribonucleic acid (DNA) is extracted according to the boiling method. Amplification conditions for KPC reactions were as follows: one cycle at $94{ }^{\circ} \mathrm{C}$ for 3 minutes, 36 cycles at $94{ }^{\circ} \mathrm{C}$ for 60 seconds, $45{ }^{\circ} \mathrm{C}$ for 60 seconds and $72{ }^{\circ} \mathrm{C}$ for 60 seconds, followed by a final extension at $72{ }^{\circ} \mathrm{C}$ for 10 minutes. Amplification conditions for GES reactions were as follows: one cycle at $94{ }^{\circ} \mathrm{C}$ for 5 minutes, 36 cycles at $94{ }^{\circ} \mathrm{C}$ for 30 seconds, $45^{\circ} \mathrm{C}$ for 40 seconds and $72{ }^{\circ} \mathrm{C}$ for 50 seconds, followed by a final extension at $72{ }^{\circ} \mathrm{C}$ for 5 minutes [18].

\section{Results}

\section{The results of isolated $K$. pneumoniae}

After culturing the samples in the MacConkey Agar medium, those colonies with a more similar appearance to K. pneumoniae which were defined as gram-negative bacteria in the straining are considered as K. pneumoniae in the first stage. In the next step, after performing catalase and oxidase tests, the samples with positive catalase and negative oxidase tests were selected. The specimens that had resulted in differential environments, according to table 3, were identified as. K. pneumoniae

From 200 K. pneumoniae strains that were collected and confirmed by biochemical method, urine and cerebral fluid were the most and the least frequent samples, respectively. (Table 4). 


\begin{tabular}{|l|l|l|l|l|l|l|l|}
\hline Biochemical tests & Catalase & Oxidase & VP & MR & Simon citrate & TSI & SIM \\
\hline K. pneumoniae & + & - & + & - & + & A/A & - \\
\hline
\end{tabular}

VP: Voges-Proskauer; MR: Methyl Red; TSI: Triple Sugar Iron; SIM; Sulfite Indole Motility.

Table 3: Biochemical traits of K. pneumoniae isolated from studied hospitals

\begin{tabular}{|l|l|}
\hline Clinical sample & Frequency (percent), $\mathbf{N}=\mathbf{2 0 0}$ \\
\hline Respiratory secretions & $10(5)$ \\
\hline Urine & $173(86.5)$ \\
\hline General secretions of ears, nose or eyes & $4(2)$ \\
\hline Blood & $2(1)$ \\
\hline Burn wounds & $10(5)$ \\
\hline Cerebrospinal fluid & $1(0.5)$ \\
\hline
\end{tabular}

Table 4: Frequency of clinical samples

\section{Antibiotic resistance pattern}

After isolating and detecting 200 samples of K. pneumoniae from clinical specimens, the resistance pattern of these strains was investigated using the disc diffusion method according to the Clinical and Laboratory
Standards Institute's criteria against different antibiotics. The antimicrobial resistance pattern of $\mathrm{K}$. pneumoniae isolates showed that the highest antibiotic resistance was against ticarcillin-clavulanic acid and the least resistance related to tobramycin. (Table 5).

\begin{tabular}{|c|c|}
\hline Antibiotic & $\begin{array}{c}\text { Frequency (percent), } \\
\mathrm{N}=200\end{array}$ \\
\hline Amikacin & $63(31.5)$ \\
\hline Gentamicin & $55(27.5)$ \\
\hline Ceftazidime & $110(55)$ \\
\hline Ciprofloxacin & $57(28.5)$ \\
\hline Ceftriaxone & $85(42.5)$ \\
\hline Cefotaxime & $103(51.5)$ \\
\hline Meropenem & $11(5.5)$ \\
\hline Ertapenem & $22(11)$ \\
\hline Imipenem & $15(7.5)$ \\
\hline Amoxicillin & $186(93)$ \\
\hline Amoxicillin-clavulanic acid & 187(93.5) \\
\hline Ticarcillin & $145(72.5)$ \\
\hline Ticarcillin- clavulanic acid & $170(85)$ \\
\hline Ampicillin & $195(97.5)$ \\
\hline Ceftizoxime & $65(32.5)$ \\
\hline Aztreonam & $142(71)$ \\
\hline Trimethoprim-sulfametoxazol & $127(63.5)$ \\
\hline Cefepime & $72(36)$ \\
\hline Piperacillin & $95(47.5)$ \\
\hline Piperacillin-tazobactam & $74(37)$ \\
\hline Levofloxacin & $96(48)$ \\
\hline
\end{tabular}

Table 5: Frequency of antibiotic resistant strains

Of the 200 strains examined, 48 strains (24\%) were resistant to imipenem, ertapenem, and meropenem. These strains were selected and subsequently used for phenotypic testing of $\beta$-lactamase production and molecular analysis of $\beta$-lactamase genes.

\section{Phenotypic test for $\beta$-lactamase}

This test is carried out to evaluate the phenotypic characteristics of $\beta$ lactamase producing strains. Among 48 strains resistant to imipenem, meropenem, and ertapenem, 15 strains $(31.25 \%)$ showed the phenotype of $\beta$-lactamase. (Figure 1) 


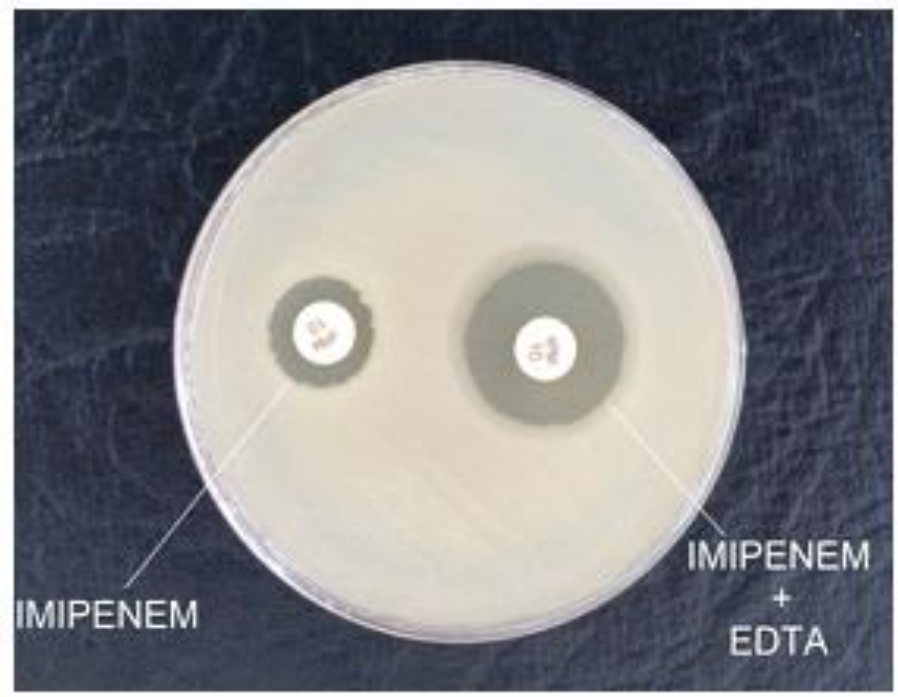

Figure 1: Phenotypic testing of a strain of $K$. pneumoniae.

The minimum inhibitory concentration (MIC) of imipenem performed on $\mathrm{K}$. pneumoniae strains resistance to imipenem, were as following: 4 strains $(1.92 \%)$ MIC $4 \mu \mathrm{g} / \mathrm{L}, 5$ strains $(2.4 \%)$ MIC $8 \mu \mathrm{g} / \mathrm{L}, 9$ strains
$(2.06 \%)$ MIC $16 \mu \mathrm{g} / \mathrm{L}, 2$ strains $(0.95 \%)$ MIC $32 \mu \mathrm{g} / \mathrm{L}, 3$ strains $(1.44 \%)$ MIC $64 \mu \mathrm{g} / \mathrm{L}, 2$ strains $(0.95 \%)$ MIC $128 \mu \mathrm{g} / \mathrm{L}, 3$ strains (1.44\%) MIC 256 $\mu \mathrm{g} / \mathrm{L}, 5$ strains $(2.44 \%$ ) MIC $512 \mu \mathrm{g} / \mathrm{L}$. (Figure 2).

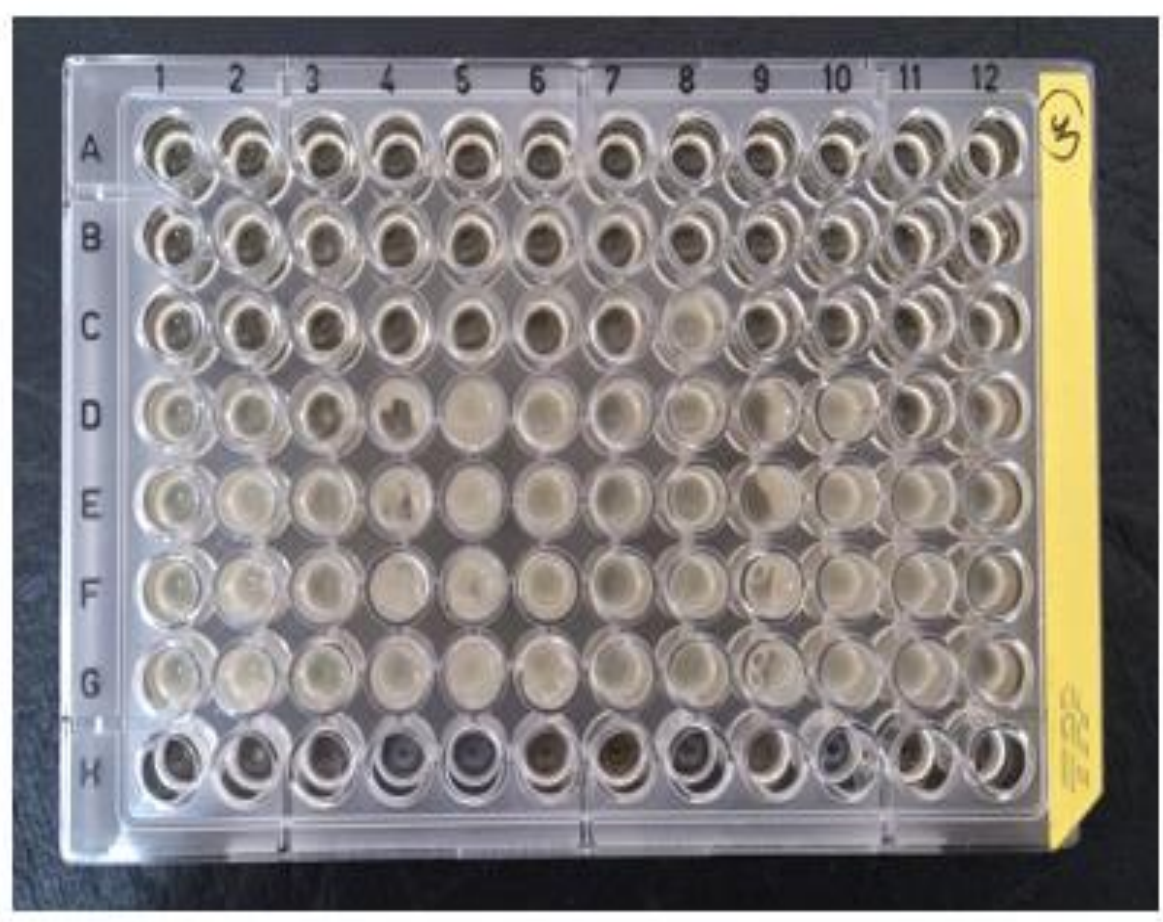

Figure 2: MIC of $K$. pneumoniae resistance to imipenem.

\section{Amplification of the GES gene}

After extraction of DNA from imipenem-resistant strains, PCR was performed for the GES gene. The results of the PCR reaction using GES primers on imipenem-resistant strains showed that of 110 strains of ceftazidime-resistant K. pneumoniae, three strains had the GES gene and subsequently 863 bp band in the PCR reaction. (Figure 3). 


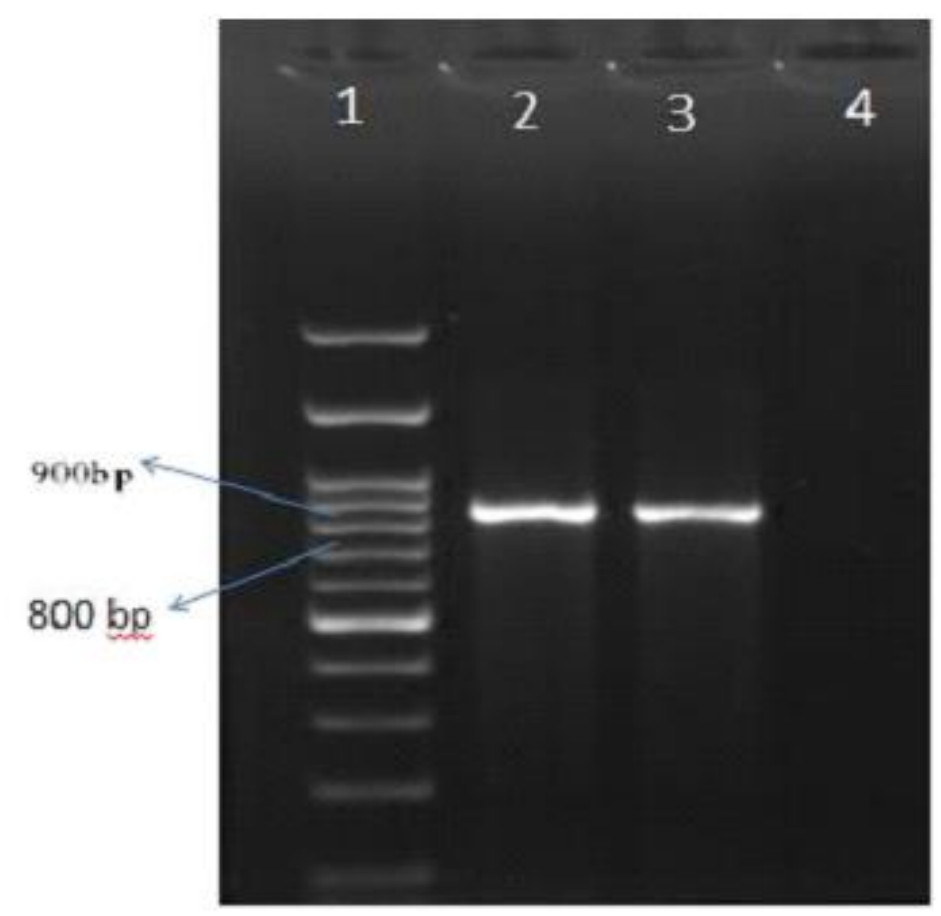

Figure 3: Results of PCR on GES gene. Column 1 marker 1500-100 bp, columns 2 and 3 K. pneumoniae isolated from clinical specimens with GES gene (863 bp) and column 4 negative control.

\section{Amplification of the KPC gene}

The results of the PCR reaction using KPC primers on imipenem-resistant strains showed that of 48 strains of imipenem-resistant K. pneumonia, none had the KPC.

\section{Discussion}

K. pneumoniae has been widely distributed in hospitals and known as an opportunistic bacterium for developing various types of nosocomial infections in hospitalized patients $[19,35,36]$. Antimicrobial resistance complicated the treatment of infections related to K. pneumoniae. The carbapenems are mostly the last line treatment for $\mathrm{K}$. pneumoniae infections and the emerging resistance to carbapenems caused a lot of concerns for the physicians [20, 21]. Carbapenems- resistance in K. pneumoniae is linked to various mechanisms, and the production of certain $\beta$-lactamases possessing even with a weak carbapenemase activity might lead to carbapenems resistance. True carbapenemases belong to ambler molecular class A such as GES and KPC, class B such as Verona integrin encoded metallo- $\beta$-lactamase (VIM), New Dehli metallo- $\beta$ lactamase and Imipenemase (IMP) or class D such as OXA-48-like and considered as the main agent for resistance to carbapenems without additional permeability defects in K. pneumoniae [22-24].

We studied the antibiotic resistance patterns and the frequency of $\beta$ lactamase genes (KPC and GES) in strains isolated from hospitals of Qom, Iran. The results showed that among 110 strains resistant to ceftazidime, 3 strains were positive for the GES gene, and the imipenemresistance isolates (48 samples) none of them had the KPC gene. The most effective aminoglycoside was tobramycin. The most effective quinolone was ciprofloxacin. The most effective $\beta$-lactam was imipenem. In other studies, with the relative increase in resistance, ciprofloxacin and its derivatives have always been the most effective quinolone, amikacin the most effective aminoglycoside, and imipenem the most effective $\beta$-lactam in the treatment of Pseudomonas infections.
In studies by Amin et al. in Pakistan [25] , Sultan Dallal et al. in Tehran [26], Ishii in Japan [27] and AL-Shora et al. in Jordan [28] imipenem is introduced as an effective antibiotic for the treatment of K. pneumoniae which was consistent with our results.

The presence of broad-spectrum $\beta$-lactamases on the transposons and their probability of movement on the genome may simultaneously express the genes' resistance. This may also result in the genes' resistance to other antibiotics of broad-spectrum cephalosporins such as the GES gene and carbapenems. The GES gene was reported by Poirel et al. in the blood culture of a patient with cerebral malaria and infectious pneumonia in a general hospital in South Africa, for the first time [29] and then in 2004 by Pastrana et al, in Argentina. Some studies were assessed the molecular characteristics and methods for GES identification. The presence of GES reduces the sensitivity to imipenem. Thus, imipenem-resistant strains are also tested for this gene [30,31].

In Japan, all strains resistant to carbapenem have been evaluated every year and only two types of metallo- $\beta$-lactamases including VIM and IMP were reported, yet. Studies showed that the prevalence of VIM in Iran was lower than that of other countries such as South Korea, Japan, and France, and probably other resistance mechanisms such as efflux pumps, defects, and lack of external membrane proteins, including outer membrane protein $\mathrm{D}$ and carbapenem class $\mathrm{D}$ are involved in producing resistance to carbapenems [32-35].

\section{Conclusions}

Long-term antibiotic uses enhance the generation of the organisms' resistance to the intended or other antibiotics. Paying attention to antibiotic susceptibility testing (AST), whether in terms of testing and reporting the results or in terms of considering the reported results at the time of prescribing and treating the disease, is of great value. Several preventive methods can use to control the prevalence of resistant 
organisms such as avoiding improper prescriptions, choosing the right antibiotic in the treatment phase, avoiding the arbitrary use of antibiotics.

\section{Authors' Contributions}

Leila Saremi, Sepideh Babaniamansour, and Marzieh Saremi were in charge of samples collection, experimental design and PCR. Razieh Nazari and Marzieh Saremi contributed equally performed and designed experiments, analyzed data, and generated figures. Razieh Nazari and Zohreh Saltanatpour were in charge of idea and concept of the paper. Leila Saremi, Zohreh Saltanatpour, and Sepideh Babaniamansour assisted in supervision. All authors read and approved the final manuscript.

\section{Acknowledgements}

The authors would like to thank the Qom Islamic Azad University of Medical Sciences for their contribution to this research.

Funding: No Financial support has been received.

Ethic approval statement: The implementation of the project was approved by the ethics committee of Qom Islamic Azad University of Medical Sciences.

\section{Conflict of interests: None.}

Availability of data and material: Data sharing is available upon the author's requests.

Patient consent statement: Informed consent was obtained from all the participants prior to the study.

Consent for publication: Not applicable.

Code availability: Not applicable.

\section{References}

1. Mehrabinejad M, Najafi A, Hajighadery A, Saraei M, Izadi N, Alemohammad Z, editors. (2019). Association of Sleep Characteristics and Respiratory Symptoms at A Smelting Factory. Sleep Medicine; Elsevier Radarweg 29; 1043.

2. Omranzadeh A, Baradaran A, Ghodsi A, Arekhi S, Dadgarmoghaddam M, Mirshekaran A, et al. (2021) Neutrophil-to-Lymphocyte Ratio as an Inflammatory Marker in Familial Mediterranean Fever: A Systematic Review and Metaanalysis. Journal of Child Science. 11(1):100-109.

3. Katsanis G.P, et al. (1994) Detection of Klebsiella pneumoniae and Escherichia coli strains producing extended-spectrum betalactamases. J Clin Microbiol. 32(3); 691-696.

4. Antimicrobial resistance: revisiting the "tragedy of the commons". Bull World Health Organ. 88(11); 805-806.

5. Omranzadeh A., et al. (2020) Mediastinal epidermoid cyst in an old man with recurrent pneumonia: A case report. Journal of Cardio-Thoracic Medicine. 8(3): 666-669.

6. Khajuria A, et al. (2014) Multidrug resistant NDM-1 metallobeta-lactamase producing Klebsiella pneumoniae sepsis outbreak in a neonatal intensive care unit in a tertiary care center at central India. Indian J Pathol Microbiol. 57(1); 65-68.

7. Kim J, et al. (1998) Survey of Klebsiella pneumoniae strains producing extended-spectrum beta-lactamases: prevalence of SHV-12 and SHV-2a in Korea. J Clin Microbiol. 36(5):14461449.

8. Mahboobi M, et al. (2020) Genetic Diversity of ctxB Gene Among Classical O1 and El Tor Strains of Vibrio cholerae using High-Resolution Melting Curve Analysis. Iranian Journal of Pathology. 15(4): 320-325.

9. Somayeh Vafaei, R.M., Nour Amirmozafari, Abbasali Imani Fooladi. (2013) Antibiotic Resistance and the Frequency of
Extended-Spectrum B-Lactamase in Acinetobacter baumannii Isolated from Clinical Samples through Phenotypic Methods. Journal of Isfahan Medical School. 31(252): 1443-1451.

10. Habibian R, et al. (2014) Virulence Factor Diversity Between Imipenem Resistant and Imipenem Susceptible Strains of Escherichia coli Isolated from Hospitalized Patients with Severe Urinary Tract Infections. Biosciences Biotechnology Research Asia. 11: 469-477.

11. Perez F, et al. (2007) Global challenge of multidrug-resistant Acinetobacter baumannii. Antimicrob Agents Chemother. 51(10): 3471-3484.

12. Nordmann P, et al. (2011) Does broad-spectrum beta-lactam resistance due to NDM-1 herald the end of the antibiotic era for treatment of infections caused by Gram-negative bacteria? J Antimicrob Chemother. 66(4): 689-692.

13. Kumarasamy, K. and A. Kalyanasundaram. (2012) Emergence of Klebsiella pneumoniae isolate co-producing NDM-1 with KPC-2 from India. Journal of Antimicrobial Chemotherapy. 67(1): 243-244.

14. Janvier F, et al. (2013) Molecular characterization of blaNDM1 in a sequence type 235 Pseudomonas aeruginosa isolate from France. Antimicrob Agents Chemother. 57(7): 3408-3411.

15. Gupta, V., P. Datta, and J. Chander. (2006) Prevalence of metallo-beta lactamase (MBL) producing Pseudomonas spp. and Acinetobacter spp. in a tertiary care hospital in India. J Infect. 52(5): 311-314.

16. Wang J, et al. (2010) Molecular epidemiology and mechanisms of carbapenem resistance in Pseudomonas aeruginosa isolates from Chinese hospitals. Int J Antimicrob Agents. 35(5):486491.

17. Nosov, N.N. Rapid method of carrying out the VogesProskauer and methyl red reactions using paper indicator systems. Lab Delo, 1984(6): 371-372.

18. Queipo-Ortuño M.I, et al. (2008) Preparation of bacterial DNA template by boiling and effect of immunoglobulin $G$ as an inhibitor in real-time PCR for serum samples from patients with brucellosis. Clinical and vaccine immunology: CVI. 15(2): 293296.

19. Salahshour F, Mehrabinejad M-M, Nassiri Toosi M, Gity M, Ghanaati H, Shakiba M, et al. (2021). Clinical and chest CT features as a predictive tool for COVID-19 clinical progress: introducing a novel semi-quantitative scoring system. European Radiology. 31(7):5178-5188.

20. Ruiz de Alegria C, et al. (2011) Klebsiella pneumoniae strains producing extended-spectrum beta-lactamases in Spain: microbiological and clinical features. J Clin Microbiol. 49(3): 1134-1136.

21. Mansouri S, et al. (2012) Characterization of Klebsiella pneumoniae strains producing extended spectrum betalactamases and AMPC type beta-lactamases isolated from hospitalized patients in Kerman, Iran. Roum Arch Microbiol Immunol. 71(2): 81-86.

22. Tonkic M, I. Goic-Barisic, and V. Punda-Polic. (2005) Prevalence and antimicrobial resistance of extended-spectrum beta-lactamases-producing Escherichia coli and Klebsiella pneumoniae strains isolated in a university hospital in Split, Croatia. Int Microbiol. 8(2); 119-124.

23. KONG, K.F., L. Schneper, and K. Mathee. (2010) Beta-lactam antibiotics: from antibiosis to resistance and bacteriology. Apmis. 118(1): 1-36.

24. Tumbarello M, et al. (2012) Predictors of mortality in bloodstream infections caused by Klebsiella pneumoniae carbapenemase-producing K. pneumoniae: importance of 
combination therapy. Clinical infectious diseases. 55(7): 943950.

25. Amin A, ghumro PB, Hussain S, Hameed A. (2009) Prevalence of antibiotic resistance among clinical isolates of Klebsiella pneumoniae isolated from a tertiary care Hospital in Pakistan. Malaysian J Microbiol. 5: 81-86.

26. Soltan Dalal, M.M. (2012) Antimicrobial resistance trends of Klebsiella spp. isolated from patients in Imam Khomeini hospital. 4: 275-281.

27. Ishii Y, et al. (2005) Evaluation of antimicrobial activity of $\beta$ lactam antibiotics using Etest against clinical isolates from 60 medical centres in Japan. International journal of antimicrobial agents. 25(4): 296-301.

28. Al Shara M.A. (2011) Emerging antimicrobial resistance of klebsiella pneumonia strains isolated from pediatric patients in jordan. The New Iraqi Journal of Medicine. 7(2): 29-32.

29. Poirel L. et al. (2001) GES-2, a Class A $\beta$-Lactamase fromPseudomonas aeruginosa with Increased Hydrolysis of Imipenem. Antimicrobial agents and chemotherapy. 45(9): 2598-2603.

30. Rahbar M., et al. (2008) Carbapenem resistance in gramnegative bacilli isolates in an Iranian 1000-bed Tertiary Hospital. Pak J Med Sci. 24(4): 537-540.

31. Nordmann P, et al. (2011) Does broad-spectrum $\beta$-lactam resistance due to NDM-1 herald the end of the antibiotic era for treatment of infections caused by Gram-negative bacteria? Journal of antimicrobial chemotherapy. 66(4): 689-692.
32. Abkhoo A, Shaker E, Mehrabinejad M-M, Azadbakht J, Sadighi N, Salahshour F. (2021). Factors Predicting Outcome in Intensive Care Unit-Admitted COVID-19 Patients: Using Clinical, Laboratory, and Radiologic Characteristics. Critical Care Research and Practice. 9941570.

33. Omranzadeh A, Hoseini Jebeli SM, Ghodsi A, Mahdavi Rashed M. (2020). Mediastinal epidermoid cyst in an old man with recurrent pneumonia: A case report. Journal of Cardio-Thoracic Medicine. 8(3):666-669.

34. Amirian A, Shahriarirad R, Mardani P, Salimi M. (2021). Nonoperative management of bilateral contained thoracic esophageal perforation: a case report. BMC surgery. 21(1):129.

35. Ghodsi A, Malek A, Ghahremani S. (2020). A review of multisystem inflammatory syndrome in children (MIS-C) associated with COVID-19.12:13.

36. Hashemi SA, Kyani A, Bathaie SZ. (2021). The in silico mechanism of hVKOR interaction with acetaminophen and its metabolite, as well as $\mathrm{N}$-acetyl cysteine: caution on application in COVID-19 patients. Journal of Biomolecular Structure and Dynamics.1-12.

37. Ogbuoji Ebuka A, Zaky Amr M, and Escobar Isabel C. (2021). "Advanced Research and Development of Face Masks and Respirators Pre and Post the Coronavirus Disease 2019 (COVID-19) Pandemic: A Critical Review" (2021). Chemical and Materials Engineering Faculty Publications. 81.
This work is licensed under Creative Commons Attribution 4.0 License

To Submit Your Article Click Here: Submit Manuscript

DOI: $10.31579 / 2690-4861 / 149$

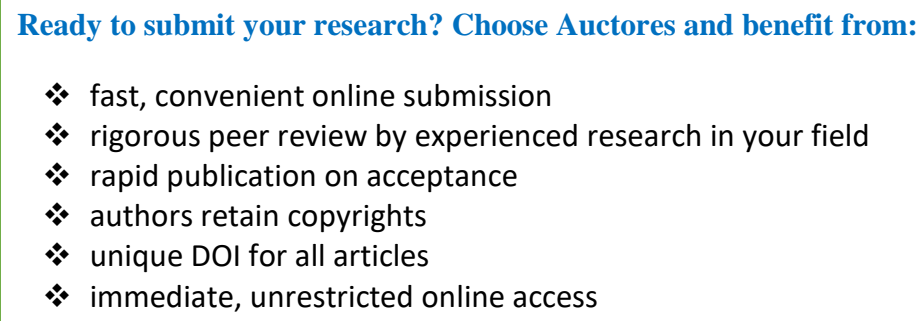

At Auctores, research is always in progress.

Learn more https://auctoresonline.org/journals/international-journal-ofclinical-case-reports-and-reviews 